\title{
Message from the Editor-in-Chief
}

\author{
Olaf Ortmann ${ }^{1}$
}

Published online: 12 July 2016

(C) Springer-Verlag Berlin Heidelberg 2016

Dear reader,

The Editorial Board of Archives of Gynecology and Obstetrics successfully improved the quality of the journal during the last years. The journal receives currently more than 1500 submissions per year from all over the world. Manuscripts mainly come from European countries, Asia, Middle East, North and South America. In addition, the readership is international. The electronic version of the journal is worldwide disseminated and available 24/7. Currently, about 10.000 institutions have access to it. In the last years, editorial management has clearly improved with a reduced duration of review processes with an average time of 15 days from acceptance to online first publication. Since 2016, the journal is available only in electronic version.

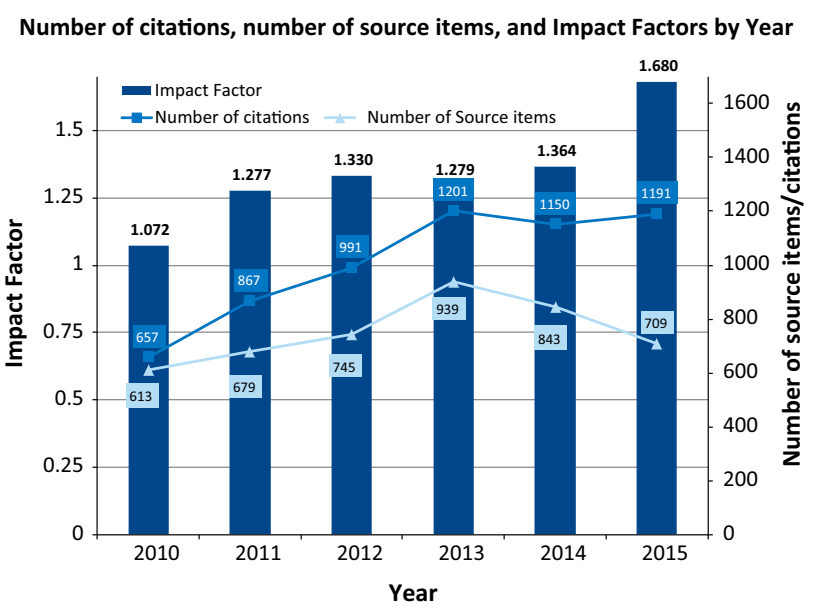

The improvement of quality is also demonstrated by an increase of the impact factor, which is currently 1.680 . Outstanding editors, associate editors, and editorial board members and reviewers have greatly contributed toward.

You are invited to submit manuscripts for publication in the different categories of the journal. Please feel free to make suggestions that will further improve its quality.

Prof. Dr. Olaf Ortmann

Editor-in-Chief

Compliance with ethical standards

Conflict of interest None.
Olaf Ortmann

olaf.ortmann@klinik.uni-regensburg.de

1 Department of Gynaecology and Obstetrics, University Medical Center Regensburg, Caritas-Hospital St. Josef, Landshuter Straße 65, 93053 Regensburg, Germany 